\title{
EL ASCLEPIO HERMÉTICO Y LA FILOSOFÍA CRISTIANA. INFLUENCIAS EN EL PENSAMIENTO Y LA TEORÍA DE LA BELLEZA MEDIEVALES
}

\author{
Francisco García Bazán \\ Universiad Argentina J.F. Kennedy-CONICET
}

\section{RESUMEN}

El artículo examina la importancia que ha tenido para los miembros de la Escuela de Chartres y especialmente para la concepción cosmológica, antropológica y estética de Bernardo Silvestre, la lectura directa del Asclepio hermético.

Para llegar a este resultado se expone la historia de las relaciones entre el Asclepio latino y el pensamiento cristiano desde el siglo II al XII y se demuestra el interés que adquieren para entender estas relaciones los escritos hermético gnósticos del Códice VI de la biblioteca copta de Nag Hammadi.

Palabras clave: Asclepio, Hermetismo, Neoplatonismo, gnosticismo, Nag Hammadi, Escuela de Chartres, Bernardo Silvestre, Estética medieval.

\section{ABSTRACT}

This paper researches the important role that the reading of the Hermetic Asclepius had to the Chartres School's members and specially for the Cosmological, Anthropological and Aesthetics conception of Bernard Silvester. To reach this result it is exposed the history of the relations between the Latin Asclepius and the Christian Thought since II to XII century and it is proved the interest of the Nag Hammadi Coptic Library Codex VI, to understand these relations.

Key words: Asclepius, Hermeticism, Neoplatonism, Gnosticism, Nag Hammadi Library, School of Chartres, Bernard Silvester, Mediaeval Aestetic

\section{INTRODUCCION}

El escrito conocido como el Asclepio hermético es la traducción latina de un opúsculo originalmente redactado en griego cuyo título primitivo es lógos téleios, el Discurso perfecto. 
Hasta mediados de la década de los años 50 se podían utilizar algunas ediciones críticas del texto, ${ }^{1}$ pero hoy, merced al hallazgo a fines del año 1945 de la biblioteca de Nag Hammadi en el Alto Egipto y su posterior edición, contamos asimismo con un extenso fragmento de este escrito traducido al copto sahídico contenido en el Códice VI, 52,1-63,32.2

Por otra parte, si bien la literatura hermética de indudable origen egipcio, ${ }^{3}$ proliferó en Alejandría durante los primeros siglos cristianos y se difundió por el Oriente, por Egipto y por el mundo bizantino, como lo confirman su conservación en lengua griega y sus versiones al armenio, copto y árabe, fenómeno comprobable tanto entre autores cristianos, como paganos y musulmanes, ${ }^{4}$ sin embargo, en el siglo XII, en pleno medioevo latino hubo un inesperado resurgimiento del hermetismo en su doble nivel, filosófico y práctico, y es entonces cuando el Asclepio, con su rico contenido cosmológico, antropológico y sotérico, adquiere entre los pensadores cristianos una vigencia de la que durante siglos había carecido, ${ }^{5}$ por más que ya con antelación se había elaborado en Bizancio la antología de libros herméticos que con posterioridad será traducida al latín por Marsilio Ficino en el siglo XV.

Lo que se termina de presentar exige ofrecer previamente un resumen de las relaciones no siempre afortunadas que han existido entre el hermetismo y el cristianismo desde el siglo II hasta la Escuela de Chartres en el siglo XII que es la que vamos a tratar.

\section{PRIMER CONTACTO CRISTIANO: EL HERMES EGIPCIO Y LA GNOSIS.}

Desde el siglo I de nuestra era se tienen noticias de la existencia de doctrinas y escritos atribuidos a Hermes, Filón de Biblos y Plutarco, ${ }^{6}$ Atenágoras, ${ }^{7}$ Hipólito de Roma,,${ }^{8}$ la Cohortatio ad

1 Cf. Scott, W.-Ferguson, A.S. (eds.), Hermetica, Oxford 1924-36, Clarendon Press (reimp. London, 1968) y Nock, A.D.-Festugière, A.J. (eds.), Corpus Hermeticum I-IV (= NF, C.H.), París, «Les Belles Lettres», 1954-1960.

2 Fragmento traducido por J. Montserrat en Piñero, A., Montserrat Torrents, J., García Bazán, F., Textos gnósticos. Biblioteca de Nag Hammadi I. Tratados filosóficos y cosmológicos, Madrid, Trotta, 1997, 421-428. La traducción alemana de los escritos herméticos incluye los tres textos de Nag Hammadi, cf. Colpe, C. und Holzhausen, J. (eds.), Das Corpus Hermeticum Deutsch I-II, Stuttgart-Bad Cannstatt, F. Frommann Verlag-G. Holzboog, 1997.

3 Cf. Derchain, Ph., «Sur l'autenticité de l'inspiration égyptienne dans le Corpus Hermeticum», en RHR 161 (1962), 175-198 y Daumas, F., «Le fond égyptien de l'hermétisme», en Ries, J.-Janssens, Y.,-Sevrin, J.-M. (eds.), Gnosticisme et Monde Hellénistique. Actes du Colloque de Louvain-la-Neuve (11-14 mars 1980), Louvaine-la- Neuve, 1982, 3-25. El hecho es negado por Festugière, A.J., cf. La Révélation d'Hermès Trismégiste I, Paris, J. Gabalda, 1950, 85-87.

4 Sobre la difusión del hermetismo desde el Egipto cf. Fowden, G., The Egyptian Hermes. A Historical Approach to the Late Pagan Mind, Cambridge, Cambridge University Presse2, 1987.

5 Cf. Lucentini, P., «L'Asclepius ermetico nel secolo XII», en Westra, H.J., (ed.), From Athen to Chartres. Neoplatonism \& Medieval Thought. Studies in Honour of Edouard Jeauneau, Leiden, Brill, 1992, 397-420.

6 Cf. Eusebio de Cesarea, Praep. evang. I,9,24 (ed., trad. y com., Sirinelli, J.- des Places, É., París, Cerf, [Sources Chrétiennes, 206] 1974, 180-181). Sobre Plutarco, De Iside et Osiride 19:358D y 54: 373B (Cole Babbit, F., Plutarch's Moralia V, London-Cambridge [MS], W.Heinemann Ltd.-Harvard Univ. Press, 1969, 48 y 130).

7 Legatio 28,4 (Ruíz Bueno, D., Padres apologistas griegos, Madrid, BAC, 1954, 695).

8 Refiriéndose a los peratas y la astrología, Elenchos V,18,8 (Marcovich, M., Refutatio omnium haeresium, BerlinN.Y., W. De Gruyter [Patristische Texte und Studien, 25], 1986, 180). 
Graecos, ${ }^{9}$ atribuida a Justino de Roma, Clemente de Alejandría, ${ }^{10}$ Tertuliano, ${ }^{11}$ Arnobio de Sicca, ${ }^{12}$ Lactancio, ${ }^{13}$ Jámblico, ${ }^{14}$ San Agustín, ${ }^{15}$ etc., aportan las referencias.

Los escritos herméticos poseen una forma literaria común: un dios (Hermes) trasmite la sabiduría sobre la esfera de lo divino, el mundo y el hombre mediante un diálogo que sostiene con un discípulo igualmente arquetípico (Tat, Asclepio [=Imhotep], Ammon [=Zeus]).

El dios Hermes, entendido como conservador y trasmisor de la sabiduría sagrada, encubre bajo nombre griego, la realidad del dios egipcio Thot y de sus funciones creativas prominentes para la piedad egipcia, por eso en estos escritos traducidos al griego recibe el apelativo propio de «tres veces» aclamado como «máximo» (tris-mégistos), 0 sea, «Thot más que máximo». ${ }^{16}$

Estas escrituras sagradas de origen sacerdotal, se fueron haciendo públicas primero en el Egipto helenizado, en la zona del Delta, y más tarde en el resto del mundo grecorromano, a partir del siglo I de nuestra era, y son la reacción de la vieja tradición sacerdotal egipcia frente a la cultura helenística mostrando en la misma lengua invasora, la riqueza y capacidad de pervivencia de una tradición religiosa, la de mayor piedad de la antigüedad para sus cultores, que era varias veces milenaria como lo ratifican las Historias que habían emprendido con anterioridad los sacerdotes y astrólogos, Nekepso, Petosiris y Maneton. ${ }^{17}$

Los escritos herméticos redactados en griego que son familiares llegaron a Italia en el siglo XV. El fraile Leonardo de Pistoia trajo desde Macedonia un manuscrito conteniendo catorce de estos tratados y Cosme de Médicis atraído por su contenido solicitó su traducción al latín a Marsilio

9 Cohortatio ad graecos 38,30-33 (Marcovich, M., Pseudo-Iustinus, Berlin-N.Y., W. De Gruyter [Patristische Texte und Studien, 32], 1990, 78), cita de fragmento I de J. Estobeo (Festugière, A.J., Corpus Hermeticum II, Paris, Les Belles Lettres, 1954, 2). Ver la relación con Platón, Timeo 28C y las reflexiones sobre la complejidad de la frase en Pépin, J., «Linguistique et théologie daris la tradition platonicienne», Linguaggio, Scienza, Filosofia, Teologia, Padova, Editrice Gregoriana, 1981, 23ss.

10 Stromatéis VI,4,35. Clemente de Alejandría conoce los libros de Hermes y describe el contenido. Bardesanes en el Libro de las leyes de los países, se refiere también a la astrología hermética y registra: «Libros egipcios en los que se describe todo lo diverso que puede acaecer a la gente», cf. Fowden, G., 0.c., 203.

11 Adversus valentinianos XV,1 (Marastoni, A., Padova, Gregoriana Editrice, 1971, 72; ver n. pp. 165-166 con referencia a De anima 28,1 y comentarios. Cf. igualmente NF, CH IV, 104).

12 Adversus nationes II,13 (McCracken, G.E., Arnobius of Sicca, The Case against the Pagans I, Westminster, MA, 1949, p. 126).

13 Instituciones divinas, passim, e igualmente Cirilo de Alejandría en el libro I del Contra Juliano, ver NF, C.H. IV, 105-114 y 126-144; y Fowden, G., 0.c., 205-206 y 180, respectivamente, y sólo para Cirilo y sus fuentes introductoras (Cohortatio y Sobre la Trinidad de Dídimo el Ciego), cf. Malley, W.J., Hellenism and Christianity, Roma, Univ. Gregoriana Ed., 1978, 258-261.

14 Cf. De mysteriis I,1 y 2; VIII, 1-5; In Tim. fr. 38. Damascio, Vida de Isidoro, fr. 3 declara que el origen de la teúrgia es egipcio (ver Fowden, G., o.c., 134-141). Sobre la relación de los tratados hermético gnósticos y Jámblico, cf. García Bazán, F., «Jámblico y el descenso del alma: síntesis de doctrinas y relectura neoplatónica», en Syllecta Classica 8 (1997): Iamblichus: the Philosopher, Blumenthal, H.J.- Finamore, J.F (eds.), 129-147.

15 De civitate Dei VIII, 23-26 y ver más abajo.

16 Cf. Daumas, F., art. cit. en n. 3. 7-10.

17 Sobre las relaciones de los egipcios desde la fundación de la dinastia ptolomaica (Ptolomeo Soter, 305 a. e. c.) en adelante, con persas, romanos y bizantinos, medio cultural en el que aparecen los libros herméticos, ver la síntesis de Copenhaver, B.P., Hermetica. The Greek Corpus Hermeticum and the Latin Asclepius, Cambridge, Cambridege Univ. Press, 1992, XVI-XXXII. Ver además, Fowden, G., o.c. 155ss y Verbrugghe, G.P. \& Wickersham, J.M., Berossos and Manetho. Introduced and translated. Natives Traditions in Ancient Mesopotamia and Egypt, Ann Arbor, The Univ. of Michigan, 1996. 
Ficino, quien debió suspender la tarea de versión de los diálogos de Platón en que estaba empeñado. ${ }^{18} \mathrm{M}$. Ficino estaba al frente de la Academia Platónica de Florencia creada por los Médicis a instancias del platónico bizantino Jorge Gemisto Plethón para contrarrestar con su labor la influencia que el Aristóteles averroísta había sembrado en Occidente. ${ }^{19}$

El volumen de escritos herméticos que llegó a manos de Ficino era una colección de textos seleccionados por un autor bizantino desconocido en torno al siglo XI, puesto que Miguel Pselo lo ha conocido, pero otros escritores anteriores nada dicen de ella ${ }^{20}$ Sin embargo, como se ha indicado antes, autores más antiguos, sabían de la existencia de una literatura hermética e incluso en algunos casos han conservado largos extractos de sus libros.

Juan de Estobeo, por ejemplo, en el siglo VI en la Antología de diversos autores y filosofías que elaboró para la educación de su hijo Septimio, ha reteniclo unos cuarenta fragmentos de escritos herméticos y hasta uno completo y bastante antiguo, La pupila del mundo (kóre kósmoul).21 Autores cristianos como el (Pseudo) Cipriano y Cirilo de Alejandría han trasmitido asimismo importantes fragmentos griegos y desde el siglo $V_{2}$ y posiblemente antes, ha circulado a lo largo del Medioevo una traducción latina sobre una enseñanza impartida a Asclepio. ${ }^{22}$

Este conjunto de fuentes completas o fragmentarias que incluye otros materiales descubiertos y agregados en el curso del tiempo, recibe la denominación convencional de los hermetica. Como género específico se ha debido sorpresivamente ampliar en el último tercio del siglo XX.

El descubrimiento, edición y traducción al ruso en 1928 y posteriormente al francés en 1976 y 1982 de las Definiciones de Hermes Trismegisto para Asclepio conservadas en lengua armenia, muestran no sólo que el estilo de algunos tratados herméticos (ver asimismo C.H. XI) hunden sus raíces en la tradición de la enseñanza sapiencial egipcia, en comparación con libros como la Sabiduría de Amenemope, o más recientes, como da testimonio el papiro Insinger, ${ }^{23}$ sino asimismo que las formas más antiguas de la alquimia, la astrología y la magia según las practicaban los sacerdotes en los templos del Alto Egipto, en Menfis, en Tebas, en Hierópolis e incluso en Panópolis, como lo ratifica el alquimista Zósimo originario de esta última región, correspondín a una etapa de actividades autorrealizativas que se completaban con un nivel espiritual. Es lo que antes que la «vía de salvación de Hermes» (Jámblico), fue el «camino de Thoth», como ya anticipara Heródoto. ${ }^{24}$

18. Cf. Allen, M.J.B. «Marsile Ficin, Hermès et le Corpus Hermeticum», en Faivre, A. (ed.), Présence d'Hermès Trisnégiste, Paris, A. Michel, 1988, 110-119.

19 Cf. Tambrun-Krasker, B., Oracles Chaldaüques. Recension de Georges Gémiste Plêthon, Athens-Paris-Bruxelles, J. Brin, 1995, 41- 47 en donde so explica la formación teosofica de Gemisto Plethón recibida en Andrinópolis, en el circulo del maestro Eliseo.

20 Esta antología hermética se caracteriza por la naturaleza teórica de los escritos que reúne, sin embargo, la glosa de M. Pselo a los manuscritos hace referencia de acuerdo con otros testimonios antiguos al carácter mágico de esta doctrina, pues en ella el aspecto filosófico y el práctico (astrología, alquimia y magia) son inseparables. La separación entre un hermetismo sabio y popular, es otro de los prejuicios de Festugière, A.l. Hernétisme et mystique païenne, Paris, AubierMontaigne, 1967, 38-50.

21 Ver Festugière; A.J., C.H. III, Paris, 1954.

22 Sobre los fragmentos de Cirilo ver más arriba n. 13 y asinismo Colpe C. y Holzhausen, J., o.c., II, 590-599.

23 Cf. Mahé, J.-P., Hermès en Haute-Ëgypte II, Québec, Les Press de lUniversité Laval, 1982, 275-406; Colpe,C./Holzhausen, J., 0.C., II, 490-504.

24 Cf. Fowden, G., o. c., 75ss y 116 ss. 
Los fragmentos herméticos de Viena editados y traducidos en 1951 , son asimismo pasajes directos posiblemente del siglo II. ${ }^{25}$ Pero la importancia de todo este conjunto de datos esparcidos, es lo que más recientemente permiten ratificar los manuscritos hermético gnósticos de Nag Hammadi, encontrados en nuestro siglo en el Alto Egipto, y uno de cuyos códices contiene tres originales en relación con la iniciación hermética.

Eruditos y sabios alemanes, franceses e ingleses entre los años 1910 y 1970, basándose en las fuentes y lestimonios a su alcance y corrigiendo el imaginario generado por la fácil credulidad de los esoterizantes europeos posrenacentistas, estimaron con tesis controvertidas tanto que los escritos herméticos eran lecturas en relación con unos cultos mistéricos desaparecidos ( $R$. Reitzenstein), como que se trataba de respuestas escolares a problemas de espiritualidad comunes a una época (A.J. Festugière). ${ }^{26}$

Hoy día, sin embargo, queda probada la importancia que los tres escritos de género hermético gnóstico aludidos, que forman parte del códice VI de la biblioteca de Nag Hammadi, representan para poder configurar una imagen más precisa del hermetismo basada en la investigación de las fuentes y su contexto cultural. ${ }^{27}$

Desde el punto de vista cronológico y de las pruebas materiales estos tres originales son los más extensos y antiguos que se poseen sobre el hermetismo.

Uno de ellos, sin embargo, la breve Oración de acción de gracias, no era una pieza desconocida, pues se encontraba cerrando un texto mágico, el conocido Papiro Mimaut de la Biblioteca Nacional de París y asimismo al final de la versión latina del Discurso perfecto. En ambos casos se comprueba que era un apéndice, ya que el texto en copto que ahora poseemos declara específicamente que se trata de la continuación del escrito que le precede en el códice, el Discurso sobre el octavo y el noveno, que es un tratado completo de iniciación hermético gnóstica. Con esto quedaría fortalecida la postura tanto de la existencia anterior de misterios de culto herméticos que los gnósticos han asimilado y adaptado pneumática o gnósticamente en alención a los adeptos salidos del Egipto helenizado, como, además, el prestigio espiritual amplio que estas relecturas gnósticas habían alcanzado en la época, puesto que una plegaria por ellos recitada en los cultos reservados se ha usado para rematar tanto un himno mágico como un tratado estrictamente hermético egipcio, el Discurso perfecto ${ }^{28}$

Pero hay algo más. El tercero de los textos en relación con el hermetismo de este Códice VI de la biblioteca de Nag Hammadi en su versión al copto, es un largo extracto elegido del contenido del Discurso perfecto que comprende algo menos de la tercera parte de la versión latina, que trasmite, sin embargo, elementos ausentes en esta última y que demuestra ser una traducción más fiel al original que la copia latina, pero que además, ha seleccionado aquellas notas del tratado de base que son gnostizantes.

25 Cf. Mahé, J.-P., «Fragments hermétiques dans les Papyri Vindobonenses Graecae $29456 \mathrm{r}^{\circ}$ ef $29828 \mathrm{r}^{\circ}$ », en Lucchesi,E./Saffrey, (eds.), Mémorial A.J. Festugière.Antiquité païenne et chétienne, Genève, Cramer, 1984, 51-64; Colpe, C./ Holzhausen, J., o.c.s II, $487-489$.

26 Resumen de las diversas opiniones en Grese. W.C. Corpus Hemeticum XIII and Early Christian Literature. Leiden, Brill, 1979, 34-58. Más actualizado, Copenhaver, B.P, o.c, li-lix.

27 Cf. García Bazán, F, en Piñero, A, Montserrat Torrents, García Bazán, o,c en n. 2, 399-409.

28 Cf. Garcia Bazán, F. ibidem, 431-435, aunque Holzhausen, J, Dos Corpus Henneticum Deutsche 11, 534-535, queda vacilane. 
En el momento en que la versión latina más extensa se está refiriendo a la dualidad de sexos en Dios y a su imagen en todos los seres de modo que la actividad reproductiva universal quede garantizada, la selección gnóstica comienza en la sección inmediata en el momento apto (latín 21.15; copto 65.15) para plantear el misterio de la unión de los sexos, que sólo pueden entender «los pocos», que son los que poseen conocimiento (gnósis) y de este modo practicantes de la auténtica filosofía, o sea, aquella que buscan los amantes de la sabiduría, que es: «la ciencia (epistéme) de los seres que realmente son». Por lo tanto, se ha podido afirmar en la enseñanza secreta de Hermes:

Si deseas percibir la realidad de este misterio, percátate también de la maravillosa imagen que es el coito que se realiza entre el varón y la mujer. Cuando alcanza su plenitud, el semen brota. En este momento, la mujer recibe la potencia del varón, y el varón recibe la potencia de la mujer. El semen es el que desencadena esta operación. Por esto el misterio del coito se realiza en secreto, a fin de que la pareja natural no tenga que sentir rubor ante muchos que no comprenden el sentido de esta realidad. Cada uno de los agentes contribuye a la generación. Si el acto tiene lugar ante los que no comprenden su sentido, resulta ridículo e increíble. Se trata, además, de santos misterios de palabras y de acciones, no sólo porque no deben oírse, sino también porque no deben verse. ${ }^{29}$

Para comprender el sentido unitario del género hermético gnóstico propio de estos documentos con el presente ejemplo, proporcionamos su análisis implícito. La hermenéutica hermético gnóstica, abarca tres momentos que son de signficación ascendente. La unión de la pareja cuando logra su plenitud, cuando se concentra en su fin y origen, la operación propia de la emergencia de la semilla, es símbolo visible (eikón) de la unidad íntima y complementaria de la pareja (syzygía) espiritual andrógina, que, por otra parte, se revela para el perfecto como el misterio inagotable de la regeneración en el seno de Dios.

De este párrafo de exégesis espiritual y de realización activa que ha conducido a la tradición hermética a través del platonismo pitagorizante a sus fuentes primordiales, la de la tradición gnóstico setiana, deriva y depende el sentido de los puntos siguientes sobre antropología, animación de estatuas, auténtica cosmología, escatología apocalíptica y aspirada soteriología, que el documento desarrolla y que en este momento en razón del tema que nos ocupa sólo es posible apuntar y no exponer en detalle.

Pero todo esto quiere decir que los gnósticos han practicado en Egipto entre los adeptos del hermetismo el mismo estilo exegético de naturaleza pneumática sin límites fijados por las creencias, que con la mitología y la metafísica griegas, la religión hebrea y la cristiana. Pero en este caso se confirma una nota más. Que han transformado las prácticas de iniciación herméticas en gnósticas. ${ }^{30}$ Este tipo de hermetismo gnóstico es el que ha conocido en el siglo IV el filósofo y teúrgo neoplatónico Jámblico e incluso el alquimista Zósimo de Panópolis y así lo han dejado registrado en Sobre los misterios de los egipcios y el Comentario sobre la letra Omega, respectivamente. ${ }^{31}$

\footnotetext{
29 Cf. VI $65,15-38$.

30 Cf. García Bazán, F., «Voies de l'ésotérisme occidental: les communautés initiatiques gnostiques et herméticognostiques», en Politica Hermetica 9 (1995), 60-72.
}

31 Cf. García Bazán, F., más arriba en n. 14, y «Alquimia Ermetica», en Nuova Secondaria XII/5 (1996), 30-33. 
Pero más todavía, la temprana influencia gnóstica en los tratados herméticos es notabilísima, al punto de que en el C.H. y en orden cronológico se ofrecen:

$1^{\circ}$ tratados hermético gnósticos o que usan parcialmente las ideas gnósticas: IV, VI, I y XIII (La crátera, El Bien es Dios, Poimandres, Regeneración) y VII, XXIII, X y XI que marca la transición; $2^{\circ}$ tratados que reaccionan contra el antinaturalismo cósmico de los gnósticos (IX, XI, XIV y Ext. V); $3^{\circ}$ tratados sin elementos gnósticos, como C.H. II.

Lo descrito en relación con el contagio del hermetismo por el gnosticismo es de particular interés para la investigación sobre el Asclepio y sus influencias, pues es algo así como una cara oculta que sin ser conocida lo ha acompañado y gravitado indirectamente sobre algunos lectores medievales que lo han podido utilizar.

\section{EL ASCLEPIO Y LAS VICISITUDES DE SU TRADUCCION LATINA}

Este escrito cuyo original griego ya está redactado en el siglo III, puesto que Lactancio lo ha usado a comienzos del IV, se ha conservado en manuscritos latinos medievales por varias vías. ${ }^{32}$ Los manuscritos más autorizados son del siglo XI ${ }^{33}$ Se trata de una traducción latina del griego adaptada por un autor desconocido y que ha vivido antes del año 413, puesto que San Agustín cita y comenta algunos pasajes del escrito en tomo a la fecha citada en la Ciudad de Dios. ${ }^{34}$ Lactancio, por su parte, pero a diferencia de Agustín, ha leído con anterioridad el texto griego del Logos perfecto y no lo ha rechazado, sino que basándose en la fundamentación arqueológica pro oriental de los orígenes de la cultura ${ }^{35}$ e interpretando el desarrollo histórico sobre la base judeocristiana de las syzygia u opuestos complementarios ${ }^{36}$ transformados por gnósticos y católicos en la teología hermenéutica del typos y el antitypos, ${ }^{37}$ adapta la figura profética de Hermes y la proclama como precursora del mensaje del cristianismo. ${ }^{38}$ Se iba consolidando de este modo la línea de una historia de la salvación única, por la que la sabiduría hebreocristiana proveniente de Dios, ha precedido a cuanto es positivo en la historia de los pueblos. Los cristianos van a incluir asimismo en el desa-

32 Pruebas del original griego en Papiro Mimaut (circ 300), Lactancio, Cirilo de Alejandría, Juan Lydo y Estobeo, cf. NF, C.H. II, 275-277 y mejor, Colpe, C./Holzhausen, J., I, 233-234. Sobre los manuscritos del Asclepio en latín cf. Klibansky, R.-Regen, F., Die Handschriften der philosophischen Werke des Apuleius. Ein Beitrag zur Überlieferungsgeschichte, Göttingen, 1993 y ver Lucentini, P., «Glosae super Trismegistum. Un Commento Medievale all'Asclepius Ermetico», en Archives d'Histoire Doctrinale et Littéraire du Mojen Age (= AHDLMA) 62 (1995), 284-293.

33 Cf. NF, C.H. II, 259-264. La traducción de J. Holzhausen recoge variantes de la edición de C. Moreschini, (Teubner 1991). Ver antes, Dall'Asclepius al Crater Hermetis: Studi sull'Ermetisno latino tardo-antico e rinascimentale, Pisa, Giardini, 1985.

34 Cf. De civitate Dei VIII, 23-26 (Obras de San Agustin XVI, Madrid, BAC, 1977, I, 530-545). Citas del Asclepio en 23, 24 y 26 [NF II, 325,4-9; 326,4-327,5 y 347,3-348,14]. Ver asimismo Contra Faustum XIII, 15 y De baptismo VI, 44,87 , menos contundentes.

35 Cf. Droge, A.J., Homer or Moses? Early Christian Interpretations of the History of Cultures, Tiubingen, J.C.B. Mohr (P. Siebek) 1989, 1-11, siguiendo a A. Momigliano y M.I. Finley.

36 Cf. Pseudoclementinas 15.1-18.8 (cf. Hennecke, E. \& Schneemelcher, W, (eds.), New Testament Apocripha II, London, Lutterworth, 1965, 545-546).

37 Ver F. García Bazán, Aspectos inusuales de lo sagrado, Madrid, Trotta, 1999, cap. I: «El mito y el lenguaje».

38 Cf. fragmentos $3 a-4 c, 6$, etc. 
rrollo providencial a la filosofía griega, y de este modo la historia de la lglesia ha llegado a ser realmente historia universal de la salvación y la filosofía dentro de ella, la cristiana, como: «la disciplina única de la realmente verdadera filosofía». Eusebio de Cesarea con su gran erudición será el primer consumador de esta nueva gran visión de la historia ${ }^{39}$

Con los fines señalados Lactancio ha hecho uso de su propia traducción, no sabemos si personal o simplemente diversa de la utilizada por el Obispo de Hipona, del lógos téleios, que para él, por consiguiente, no es tanto «doctrina completa», cuanto «Logos perfecto», el Logos cristiano, Verbo trinitario, la Palabra creadora y encarnada, preanunciada por Hermes. ${ }^{40}$ Esta versión tanto literaria como exegética es la que ha sido aceptada y utilizada por el escrito pseudoagustino de un autor africano del siglo V, Contra las cinco herejias. ${ }^{41}$ Pero frente a las críticas adversas de San Agustín al Hermes egipcio, esta nueva interpretación que se fundaba y recogía la tesis de Lactancio, es la que le ha dado carta de ciudadanía al Asclepio tanto en el anónimo del siglo XII: Comentario a la Consolación de la filosofía de Boecio, como a las citas de otros autores conocidos: Sedulo Escoto, Adalberto de Utrecht y Abelardo ${ }^{42}$ Aunque al mencionar al célebre Abelardo nos aproximamos justamente a la Escuela de Chartres y advertimos la importancia que el documento adquirió entre sus miembros y, en particular, en Bernardo Silvestre, en su enigmática Cosmografía. Autor y libro en relación con su lectura del Asclepio al que nos vamos más abajo a referir.

\section{LA ESCUELA DE CHARTRES Y EL ASCLEPIO LATINO}

Se sabía, aunque con informaciones no exentas de imprecisiones, que en el siglo XII funcionaba una escuela en la localidad de Chartres en relación con su catedral en la que habían enseñado famosos maestros, entre los se advertía una cierta afinidad de pensamiento. En la última década del siglo XIX A. Clerval investigó directamente los archivos catedralicios. Esta investigación sigue siendo el trabajo básico sobre la existencia histórica de la escuela, sus programas de estudio y las listas de sus profesores. P. Chenu y J. Le Goff casi al mismo tiempo y en sendas síntesis brillantes, le dieron al tema una apariencia engañosa, debido a los rasgos excesivos que dieron a las respectivas representaciones. ${ }^{43}$ Nuevos estudios en contra y a favor han dado una imagen más equilibrada de la cuestión. ${ }^{44}$ Los pensadores sobrevivientes del reajuste académico siguen siendo: Bernardo y

39 .. Cf. Praep. evang. XI, 8-11 y ver Garćáa Bazán, F., «Dios Padre como Uno y Ser en los escritos gnósticos de Nag Hammadi. En torno a la metafísica de Exodo 3,14», en Teología y Vida 39/4 (1998), 325-344. La frase citada pertenece a San Agustin:

40 Cf. Wlosok, K., Laktanz und die philosophische Gnosis, Heidelberg, 1960.

41 Cf. R. Braun (ed.), Quodvuitdeus Carthaginensis, Opera tributa, Turnhout, Brepols, 1976. P. Lucentini en art. cit, $401, n .29$, señala las dudas sobre la continuidad de la línea agustiniana.

42 Cf. Gersh, S., Middleplatonism and Neoplatonism.The Latin Tradition I, Notre Dame (IN), Univ. of Notre Dame, 1986,329, n. 1 .

43 Cf. Chenu, M.D., La théologie au Xlle siècle, Paris, Vrin, 1957 y Le Goff, J., Los intelectuales en la Edad Media, Buenos Aires, EUDEBA, 1965, 64ss.

44 R. W. Southern (1970), J. Chătillon (1972), N. Häring (1974), R. Giacone (1974), P. Dronke (1988, 1992), E Jeauneau (1992). Ver resumen en Lemoine,M., Théologie et platonisme aux XIle siècle, Paris, Cerf, 1998. 18-21 y pgs. ss. sobre la síntesis que prosigue. 
Teodorico de Chartres, Guillermo de Conches, Clarembaud de Arrás, Juan de Salisbury y Bernardo Silvestre.

La actividad de la Escuela de Chartres puede subdividirse en tres periodos. Dentro del primero y como sus bases fundadoras se debería incluir a Adelardo de Bath y acontecimientos cronológicos paralelos como las fundaciones de San Víctor (1108) y de Claraval (1105). Sus límites temporales abarcarian hasta las muerte de Anselmo de Laon y sobre todo de Bernardo de Chartres, que fallece entre 1124 y 1126 . El segundo período sería la etapa de madurez con Abelardo y Teodorico de Chartres, maestro este último, de alumnos brillantes que lo han continuado: Guillermo de Conches, Clarembaud de Arrás y Gilberto de la Porrée que fallece en 1154. Se inicia, entonces, el tercer período, signado por la actividad de estos discípulos de Teodorico de Chartres, conjuntamente con Juan de Salisbury y Bernardo Silvestre. Debe aclararse, sin embargo, que desde mucho antes de que comenzara a funcionar la escuela chartriana existía una tradición sobre Chartres que la identificaba como el centro sagrado de la Galia ${ }^{45}$ y que durante el primer tercio del siglo XI, Fulbert, canónigo de la catedral y posteriormente obispo de Chartres, había atraído por su enseñanza a numerosos discípulos, siendo considerado un nuevo Sócrates y transfiriendo de esta manera el simbolismo de la escuela palatina de Carlomagno a la Academia Chartriana. En ella se entendía que el estudio del trivio y el cuadrivio era imprescindible para el examen de los clásicos, etapa preparatoria y previa para la lectura y estudio de la Biblia. Pero el siglo XII comienza siendo una época de emulación intelectual (Abelardo es quizás el ejemplo prototípico) ${ }^{46}$ y de distinción y rivalidad entre escuelas monásticas y catedralicias, entre el campo y la ciudad, y el momento consecutivo del auge de la creación y crecimiento de estudios y universidades. ${ }^{47}$ Un resultado sobresaliente de estas transformaciones es el engrandecimiento de la escuela catedralicia de Chartres.

El método de enseñanza de la Escuela es el de la praelectio realizada con el maestro, seguido de la lectio que cumple el discípulo ya instruido y rematado por la glosa al texto, que es su exposición profunda. Las bases textuales de la enseñanza son los poetas (Virgilio, Horacio y Ovidio) y el platonismo que se recibe por citas indirectas, pero sobre todo a través del conocimiento de Marciano Capella y S. Boecio y de los comentarios al Timeo de Calcidio y al Sueño de Escipión de Macrobio. Se deberá advertir, por tanto, que mediante el estudio de los cuatro autores aludidos, no sólo se introducía en la Escuela de Chartres el platonismo neoplatonizado de Plotino, sino asimismo el platonismo pitagorizante anterior a él (Numenio de Apamea) y el posterior que lo corrigió, o sea, el de los neoplatónicos hieráticos que encabezó Jámblico de Calcis y fructificó en las escuelas neoplatónicas de Atenas y Alejandría. Al mismo tiempo elementos difusos del pensamiento hermético se combinaban en estos comentarios. Ahora bien, a la reseña de los materiales fundamentales que se acaban de enumerar, se debe agregar que Adelardo de Bath, al que nos hemos referido más arriba, desde mucho antes había viajado a distintos puntos del Mediterráneo para conseguir informaciones de la ciencia árabe que mucho le interesaban, hasta el punto de que la integración de

45 El testimonio es de Julio César (De Bell. Gal. VI,13), pues en este lugar consagrado se reunían anualmente los druidas.

46 Cf. Dales, R. C., The Intellectual Life of Westem Europe in the Middle Ages, Leiden, Brill, 1995, 238ss.

$47 \mathrm{Cf}$. idem, 0.c., 147-168 y brevemente, Duby, G., Arte y sociedad ent la Edad Media, Buenos Aires, Alfaguara, $1999,56 \mathrm{ss}$. 
la logica vetus por la nova logica la han completado en dos etapas consecutivas Teodorico de Chartres y Juan de Salisbury. En el interior de este cuadro de enseñanza últimamente platónica, que ha aspirado a recuperar el pensamiento filosófico como la «búsqueda de la sabiduría» plena que se trasmite en la escuela, que ha tomado el texto escrito como envoltorio (integumentum) o narratio fabulosa (=mythos) que encierra un sentido oculto o subyacente para ser descubierto y no mostrarse al intérprete superficial, es en el que se inserla como una cadena escolar que remonta a Homero, Bernardo Silvestre. Por ese motivo el Asclepio hermético va a representar para él una clave central de interpretación que no contradice a Platón y al cristianismo, sino que coadyuva con ellos para poder producir una obra mayor, la Cosmografía, en la que la autonomía del mundo, de la naturaleza y del hombre, no se oponen a Dios Padre y su Providencia, sino que la promueven.

Efectivamente, las ideas herméticas, como se ha afirmado más arriba, venían asimiladas y autorizadas para los pensadores de Chartres como una dimensión del platonismo en las Nupcias de Mercurio y Filologia de Marciano Capella ${ }^{48}$ y el Comentarium in somnium Scipiopnis ${ }^{49}$ de Macrobio, pero no sólo esto, sino que el Asclepio, obra identificada como de Hermes desde San Agustín, en el renacimiento carolingio adquiere autonomía, de manera que a partir del siglo IX viene incluido en los manuscritos de las obras de Apuleyo, aunque con beneplácito para su contenido garantizado por la interpretación del desconocido, amigo y corresponsal de Agustín y después Obispo de Cartago que escribió bajo el nombre de Qudvultdeus Carthaginensis inspirado a su vez en la interpretación de la doctrina de Hermes como precursora de la enseñanza cristiana del Verbo de Lactancio y otros escritores cristianos, como hemos explicado más arriba. ${ }^{50}$ Esta particularidad no sólo autorizaba a una lectura cristiana del escrito, sino que asimismo daba estímulos para dar mayor profundidad histórica y originalidad a la filosofía cristiana tradicional. Del primer paso designado son testimonio varios de los representantes chartrianos que son anteriores a Bernardo Silvestre, pero de ambos, éste último. Efectivamente, el Asclepio ha sido familiar y asimismo citado como autoridad tanto por Abelardo como por sus seguidores, ${ }^{51}$ pero dentro del círculo más estrecho de Chartres, ha sido personalmente leído por Teodorico de Chartres, llevándole a aproximar el neoplatonismo al cristianismo en sus reflexiones sobre el alma del mundo y el modo de relación entre el uno-todo y lo múltiple. ${ }^{52}$ Ermanno de Carinzia lo seguirá a su maestro ${ }^{53}$ igual que Bernardo Silvestre. Otro adherente será Juan de Salisbury, ${ }^{54}$ y con posterioridad a Bernardo Silvestre seguirá usándolo Alano de Lille, ${ }^{55}$ pero asimismo el autor de un manuscrito anónimo que desarrolla una

48 Cf. Martianus Capella, edidit J. Wiltis, Leipzig, Teubner, 1983 y Gersh, S., o.c, vol II, 597-646.

49 Cf. Stahl, W.H, Macrobius, Commentary on the Dream of Scipio, New York, Columbia Univ, Press, 1952; Flamant, J., Macrobe et le néoplatonisme latin, à la fin du IVe siècle, Leiden, Brill, 1977 y Gersh, S., o. c., vol. II, 493. 595.

50 Cf.n. 41.

51 Cf. Theol, summi boni 1,35: «Primus autem nunc ille antiquissimus philosophorum et magnis nominis occurrat Mercurius, quem preexcellentia sua deum quoque appellaveruntsy III,54-55. Ver Sic et non 15; Theol. Christiana I,61 y Theol. scholarium I, 115, etc. (ef. Lucentini, P., art. cit. en n. 5, 403, n. 46 y 403-405).

52 Cf. Tractatus de sex dierum operibus 22-26 y Closa, Commentum y Lectiones super Boethii libium De tinitate: II,21 y 2,9-10; 4,7-8; 4.71, respectivamente, con los comentarios de Lucentini, P., art, cit, 406-410.

53 Ermanno de Carinzia en De essent. usa a menudo el Ascl. uniéndolo con las noticias herméticas extrádas de su versión del Introductoritum maius de Albumasar (ver Lucentini, P., 401, nn. 31 y 32 y 410-411).

54 Cf. Policraticus II,28 (Lucentini, P., I.c., 401, n. 30).

55 Cf. Sunma Quoniam homines 4, 8, 9, etc. y Contra haereticos (ver Lucentini, P., art. cit, 413-415). 
extensa glosa de aspectos seleccionados del Asclepio. Este escrito redactado a fines del siglo XII o comienzos del XIII, deja ver fuertes influencias de Alano de Lille sobre el escritor y ratifica definitivamente el relieve que la figura y enseñanza de Hermes había adquirido en este medio de la filosofía cristiana. ${ }^{56}$ Naturalmente cuando Alberto Magno y particularmente Tomás de Aquino se refieren a Hermes, su enseñanza y prácticas, lo hacen en signo de respeto a su doctrina, pero precisamente para engrandecer la cristiana como culminación de ideas prefigurativas, ${ }^{57}$ a través de la ciencia de un Aristóteles carente de contexto escolar.

Es muy posible que el manuscrito del Asclepio que ha leído y meditado a fondo Bernardo Silvestre haya sido el ejemplar de la biblioteca de Chartres que había usado el mismo Teodorico, a quien dedica su Cosmografia. Sin embargo, el empleo que Bernardo Silvestre ha hecho de la tradición hermética y platónica, las ideas que le han inspirado y las consecuencias que ha podido extraer en concreto de la lectura del Asclepio lo han llevado por caminos del pensamiento diversos $y$ de una poderosa y compleja originalidad.

\section{BERNARDO SILVESTRE Y LA COSMOGRAFIA: EL UNIVERSO Y EL HOMBRE COMO VIVIENTES BELLOS}

Bernardo conocido como Bernardus Silvestris por sus elucubraciones sobre la materia (silva), ha sido discípulo o un admirador muy próximo a Teodorico de Chartres, puesto que a él le dedica su obra más famosa, ${ }^{58}$ miscelánea de prosa y verso (prosimetrum), escrita en torno a $1147-1148 .^{59}$ La obra dividida en dos partes dedicadas al megacosmos o universo viviente, y al microcosmos o ser viviente humano, se presenta como un gran relato, en el que los personajes dramáticamente se presentan, dialogan y reflexionan. Los manuscritos facilitan el siguiente resumen:

«En el libro primero de esta obra, que lleva por título Megacosmos, o sea, "gran mundo", Naturaleza, casi llorando, se lamenta ante el Nous, es decir la divina Providencia, por la confusión en que se encuentra la materia primera, o sea, Yle, y le ruega que otorgue al universo una belleza de mayor elegancia. Nous, entonces, conmovida por sus plegarias, accede con gusto al ruego y separa entre sí a los cuatro elementos. Emplaza en los cielos a las nueve jerarquías de ángeles, fija las estrellas en el firmamento, dispone las doce constelaciones, permite que circulen las órbitas de los siete planetas por el Zodíaco y coloca en los puntos cardinales cuatro vientos que respiran uno contra el otro.

Sigue la creación de los vivientes y el emplazamiento de la Tierra en el centro del universo. Después se describen las montañas notables; se fija después la naturaleza propia de cada uno de los animales; se describen a continuación los rios famosos y la naturaleza peculiar de los árboles; des-

56 Cf. Lucentini, P., art. cit, más arriba en n. 32, 189-282.

57 Cf. F. Hudry, Liber viginti quattuor philosopharum, Turnholt, Brepols, 1997, Int., XXVIII-XXXI. Sobre otras vías paralelas de introducción del hermetismo a través de las traducciones del árabe, ver Kahn, D. Hermès Trismégiste, La Table d'Émeraude et sa tradition alchimique, Paris, Les Belles Lettres, 1995 y Silverstein, T, «Liber Hermetis Mercurii triplicis De VI rertm principis», en AHDLMA 30 (1955), 217-302.

58 «Bernardo Silvestre dedica st obra a Teodorico, doctor muy famoso por su sabers, in initio.

59 Fecha en que la obra se ha recitado en Tours ante el Papa Eugenio III (ver Cosmografia I, iii, 50-60). 
pués las especies aromáticas, la diversidad de legumbres, la naturaleza propia de los cereales y las propiedades de las hierbas; más tarde la variedad de los animales acuáticos y volătiles. Después de lo cual se trata de dónde venga el origen de la vida de los seres animados. De este modo, en el libro primero, se describe la ordenación de los elementos.

En el libro segundo, que lleva el título de Microcosmos, o sea, "pequeño universo", Nous se dirige a Naturaleza, se honra por el embellecimiento del universo y declara que para dar conclusión a su obra, plasmará al hombre. Por lo tanto le manda que busque con solicitud a Urania, reina de las estrellas, y a Physis, experta conocedora de todas las cosas. Naturaleza obedece enseguida al mandato y buscando a Urania a través de los círculos celestes, la encuentra contemplando admirada a los astros. Urania que sabía el motivo de su viaje, le promete que será su compañera tanto en la actividad como en el viaje. Las dos, pues, se ponen en camino y después de haber recorrido las órbitas de los planetas y conocido sus poderes de influencia, descubren finalmente a Physis, sentada entre sus dos hijas, Teórica y Práctica, en el seno de la Tierra, lujuriante e impregnado de perfumados aromas, explicándoles la causa de su venida. Sin esperarla se hace presente Nous y después de manifestarles su voluntad, les asigna tres modalidades de contemplación que atribuye a cada una, impulsándolas a plasmar al hombre. Physis, por lo tanto, forma al hombre con lo que queda de los cuatro elementos. Comienza por la cabeza, procede miembro por miembro y termina felizmente su obra, llegando hasta los pies $\%$

Los personajes de la narración que interesa destacar y el significado que subyace a sus personificaciones y funciones son las siguientes:

Nous es la realidad divina a la que se dirige Naturaleza para que Dios Padre no se aleje en su soledad. Es la figura central del drama, como entidad intermediaria entre la divinidad aislada y el universo viviente y habitado por el hombre. Las caracterizaciones que le corresponden marcan, por consiguiente, tres aspectos: $1^{\circ}$ entidad divina o consustancial al Dios primero y que de él emerge («divinidad, primogénita de Dios» - deus, prima orta Deus-; «sustancia de lo Verdadero»substancia veri-; «continuidad del consejo etemo» - consilii tenor eterni- y «Mnerva verdadera $\gg)_{.}^{61} 2^{\circ}$ Divinidad inseparable de Dios al que expresa como pensamiento y voluntad («Intelecto divino» - intellectus dei-; «Pensamiento del Altísimo» - mens altissimi-; «Pleroma de la ciencia divina» - divina plenitudo scientia-y «Bien de la Bondad»-bonum bonitatis-)..$^{62} 3^{\circ}$ En consecuencia, ser divino que encierra la potencia circunscripta de la fecundidad ilimitada del Padre ( (Imagen de la Vida que vive»-vite viventis imago-; "Sin cesar encinta de la Voluntad divina» $y$ «Semillero de vida» - Seminarium vite-). ${ }^{63}$

Si Dios Padre.(Deus, Usía prima, Tugaton [= to agathón] es unidad, sobre todo intelecto e incircunscripto, donador espontáneo y por encima de la división de los sexos, necesita de Nous para manifestarse providencialmente en ella. ${ }^{64}$ En este sentido correlativo puede afirmarse que su actividad progenitora es activa y masculina, en tanto que Nous como receptáculo eterno y dócil del

60 Cf. Edición de Dronke, 95. Ver más abajo n. 75.

61 Cf. Cosnografia I, i,5-8 (ver M. Capella 1,$25 ; 1,92$ ) y $1,1,62$.

62 Cf. Cosmografia 1,1,4 (Macrobio, In Somn Scipionis 1,14,6); 1,ii,1 y 2; 1,iii,18; 1,iv.5-6 (ver Ase 41 in init y 8,20 y 26); $1, i v, 9-11$ y $1, i v, 14$ (Asc 20).

63 Cf. Cosmografía 1,1,8-9 y 1,1,54-55; 1,ii,3,7 y 8 (ver más abajo Asc 41); 1,11,11 (cf Gén 1,10, Tmeo 37C, Asc 3).

64 Cf. Cosmografia $1, \mathrm{i}, 11-15 ; 1, \mathrm{~N}, 4$ y $5 ; \mathrm{II}, \mathrm{v}, 3 ;$ vii, 5 y xiii, 1 . 
querer y conocer paternos indiscernibles es correlativamente femenina, pero en sí misma unión de contrarios y respecto de los sexos, andrógina, y de acuerdo con esto funciona generativamente, puesto que su sabia feminidad al mismo tiempo que recibe completamente al Padre ( $«$ Sí mismo como otro sí mismon), lo irradia y desborda desde sí, activa y varonilmente (fons lumini y seminarium vite).

Por su género en relación con Dios Padre permitiéndole revelarse es una entidad femenina, pero por su actividad fecunda asimismo en nexo inseparable de Dios, es una figura andrógina como una esposa que al mismo tiempo es hijo-hija, que todo lo posee, porque es cuanto alcanza del Bien. ${ }^{65}$

Silva/Yle. En el extremo opuesto a Nous se encuentra Silva, la materia. Efectivamente si Nous es plenitud de la voluntad divina, este estado de estabilidad total alcanzado implica que debe haber un deseo en sí incompleto y otro (diversum) que Dios, que permanecerá fuera de Nous y siempre necesitada de satisfacerse. No se trata de que quiera arrebatar la luz del bien, sino de que su debilidad lo necesita y nunca lo puede obtener completamente, éste es su mal primordial. ${ }^{66}$ De este modo la materia se muestra como potencia que siempre estuvo inteligiblemente en el Nous y que se concreta como creación primera en el tiempo. Por eso es la más anciana entre los seres creados y siempre necesitada de engendrar un hijo, el mundo ${ }^{67}$ En su naturaleza entregada a sí misma es caos informe, por consiguiente, con una disposición connatural a engendrar como el más débil efecto de la creación y el más persistente y universal de los deseos, necesita de las formas ordenadas en el tiempo y en el espacio para mostrar orden y belleza. ${ }^{68}$

Yle es lo femenino en sí mismo, receptáculo fecundo y apetitivo, insaciable como lejanía indefinida del Padre y que se eleva y satisface no en ella misma, sino cuando desde su seno (gremium) materno, da a luz (silva parens) vástagos con forma.

Por esa razón Natura clama a Nous, porque es testimonio de su necesidad de útero universal. Ya que Naturaleza es el lazo que une a Nous con materia. Representa ella a la organizadora universal. A la gran potencia demiúrgica, hija primera de Nous, que desde el caos del deseo materno instrumenta la gran partenogénesis originada en la unión del apetito desordenado de materia con la voluntad/conocimiento de Dios Padre revelado en Nous/Providencia, Madre que todo lo engendra en el silencio y reposo. El orden orgánico y su simpatía, sideral y sublunar, en el tiempo y en el espacio (Eimarmene), desde la aparición de los elementos masivos a los astros brillantes y matemáticamente reglados de ella depende y ella lo inicia ${ }^{69}$ pero el superior ornato particularizado y la coordinación orgánica del gran viviente universal, necesita la colaboración de sus hermanas menores: Urania que habita el cielo y lo asiste y ve en su orden como reflejadas en un espejo las ideas de Nous y los decretos divinos, ${ }^{70}$ y Endelichia, Alma del mundo, que ve en si misma el orden uni-

65 Cf. Cosmografia I, iv 14 y Asc 20. Anảlogamente se dice de Naturaleza que es «fecundable y fecunda» $(1,11,6)$. Dentro de la continuidad de lo real, difieren sólo los extremos. Dios es fecundo y la materia fecundable.

66 Cf, II,xiii, y y ,ii,2. En relación con la díada como alteridad, ver García Bazán, F. «Los aportes neoplatónicos de Moderato de Cádiz», en Anales del Seminario de Historia de la Filosofía 15 (1998), 15-36.

67 C. I,i,31-41 y 56-64; l, ,ii, y 5 ; liv, 4 y 7 in init; II,xi.5.

68 Cf. I,i,8-9, 18-30, 40-50 y 56-57; I,ii,2, 5 y 6 (ver Asc 25 y n. 81); I,ii, 7,8, 13 y 16 in fin; I,iv, 18; II, 11, 1-3; II,xiii,3.

69 Cf. I, i, $3 ; 1, i i, 1,6,8$ y $10 ; 1$, iv, $7 ;$ II, xi, 3 y $6-8$.

70 Cf. II, iii, 3,6 y 12; II, iv, I-55; II,Xi,3-4; II, xii, 1-65. 
versal y ocupada en él, lo trasmite como principio de vida y movimiento moviente de los planos inferiores del universo, fortificando de este modo la acción de Naturaleza. ${ }^{71}$

Physis, por otra parte, se ocupa en la obra de generación de los cuerpos orgánicos innumerables aptos para recibir la vida y ser oportunamente animados, así como de los recursos que los pueden sostener y conservar. ${ }^{72}$ Convive con sus dos hijas, Teórica y Práctica, en el lugar propio del seno generativo de la Tierra, el Gramision, que ya no es la gran matriz caótica impulsada por los movimientos de la potencia informe, sino el útero predispuesto por la cosmificación de Naturaleza y sus colaboradoras, como auxiliadores de Nous, para recibir las semillas ideales que le dan vida particular y ornato al universo. ${ }^{73}$ Por eso en este lugar Naturaleza conjuntamente con Urania visitan a Physis, Teórica y Práctica, para la formación del hombre. ${ }^{74}$

\section{EL MEGACOSMOS-MICROCOSMOS Y LA INFLUENCIA DEL ASCLEPIO. ICONOGRAFIA Y BELLEZA}

Los años de la década del 70 han conocido dos traducciones a lenguas modernas de la Cosmografía y una edición crítica, la del 80 una tercera y la nuestra, otra diferente, la más reciente y que se apoya en un texto crítico inédito de J. Vernet. ${ }^{75}$

Sin embargo persisten serias dudas sobre la interpretación de este magnífico texto. Las incertidumbres son alimentadas por el predominio casi exclusivo de figuras femeninas de la narración, todas ellas, salvo el Dios Altísimo-Tugatón, y el enigmático carácter femenino del Nous o Intelecto.

Los estudios que se han sucedido desde 1928 queriendo explicar la naturaleza cristiana ortodoxa de la obra, su visión de conjunto, o bien, sus ricas sugerencias literarias y doctrinales, no han alcanzado el objetivo que propone nuestro subtítulo. ${ }^{76}$

Es necesario ahondar la lectura realizada por Bernardo Silvestre del Asclepio, la que ha sido decisiva tanto para la composición de su obra maestra como para plasmar su concepción de la belleza.

71 Cf. I,ii, 13 in fin y $14,15,16 ;$ II,xi,5.

72 Cf. II,iii,3; II,xi,3 y 10-11; II,xiii,2-6.

73 Cf. II,ix, 2-8. y ver. Jolivet, J., «Les principes féminins dans la "Cosmographia" de Barnard Silvestre», en Wenin, Ch. (ed.), L'Homme et son univers au Moyen Age I, Louvain-la-Neuve, Éd. de l'Institut Supérieur de Philopsophie, 206-305.

74 Cf. Cosmografia II,xi, 1 ; II,xiii,7-15; II,xiv, 1-183.

75 Cf. Wetherbee, W., The Cosnographia of Bernardus Silvestris. Translated with Introduction and notes, New York, Columbia Univ. Press, 1973; Maccagnolo, E. (ed.), Il Divino e il Megacosmo.Testi Filosofici e Scientifici della Scuola di Chartres, Bernardo Silvestre, Cosmografia, Milano, Rusconi, 1980, 459-552; Dronke, P. (ed.), Bernardus Silvestris, Cosmographia, Leiden, Brill, 1978; Rath, W., Über die allumfassende Einheit der Welt. Makrokosmus und Mikrokosmus (trad. y com.), Stuttgart, Mellinger, 19892; Lemoine, M., Bernard Silvestre, Cosmographie (trad., int. y notas), Paris, Cerf, 1998.

76 Cf. estos trabajos críticos que examinan a los anteriores: Gilson, E., «La cosmogonie de Bernard Silvestre», en AHDLMA 3 (1928), 5-24; D'Alverny, M.-T., «Le cosmos symbolique du XIle siècle», ibídem, 28 (1953), 31-81 y, en particular, Silverstein, Th., «La favolosa cosmogonia di Bernardo Silvestre», en ídem (ed.), Poeti e Filosofi Medievali, Bari, 1975, 13-63, trad. al italiano del art. publicado en Modern Philology 46 (1948) y más recientemente, Ziomkowski, R., «The Cosmographia of Bernardus Silvestris as a Mystical Text», en The Journal of Neoplatonic Studies IV/1 (1995), $77-119$. 
Pero debe tenerse en cuenta con este fin que no sólo es importante señalar el vocabulario común de los dos escritos, ${ }^{77}$ sino asimismo algunas ideas centrales y peculiares de la Cosmografía.

$1^{\circ}$ La naturaleza femenina del Nous, nota sin la que la concepción cosmológica, antropológica y estética de Bernardo Silvestre carecería de base, le ha sido inspirada por el Asclepio.

La oración que cierra el Asclepio latino dice en las líneas que nos interesan: «Oh, verdadera vida de la Vida, oh, embarazo fecundo (fecunda praegnatio) de todo lo que ha de nacer, te hemos conocido, por tu concepción de toda naturaleza plenamente, residencia eterna <del Padre que genera>, te hemos conocido. En toda esta plegaria, pues, los que adoramos el bien de tu Bondad, esto te pedimos...». La versión latina podría desorientar, pero hoy conocemos con mayor precisión el sentido más profundo que estas líneas encierran, que tampoco son diferentes de las que se conservan en griego al final del Papiro Mimaut y que Bernardo Silvestre sabía leer correctamente en un latín que era afín a sus sentimientos, ya que la Oración de acción de gracias del NHC VI, lo ha trasmitido en copto del siguiente modo: «Te hemos conocido, oh luz inteligible, oh vida de la vida, te hemos conocido. Oh matriz (métra) de toda generación, te hemos conocido, oh matriz que concibe en la naturaleza del Padre, te hemos conocido, oh permanencia eterna del Padre que genera, de este modo hemos rendido adoración al Bien (agathón). Te pedimos un solo deseo». ${ }^{78}$

Ningún contenido presuntivamente incógnito hay aquí. Sólo que las líneas del Asclepio que al intérprete gnóstico daban pie para entender un seno de Dios que atesoraba un Intelecto primogénito de acuerdo con un conocido tecnicismo propio, a Bernardo le permitían comprender una mente divina, expresión del pensar y querer del Padre, encinta, pues, por él de la previsión de lo que había de crearse.

$2^{\circ} \mathrm{La}$ actividad autogenerativa, autoexpansiva o silenciosamente andrógina de los principios generadores. $^{79}$

$3^{\circ} \mathrm{La}$ menesterosidad o fecundidad difusa de la materia como imagen sensible postrera y debilísima, siempre necesitada de concebir formas que la delimiten. ${ }^{80}$

77 Ideas anticipadas por E.R. Curtius, entre otros, pero analizadas con especificidad por Woolsey, R.B., «Bemard Silvester and the Hermetic Asclepius", en Traditio 6 (1948), 340-344, quien ilustra cinco puntos: $1^{\circ}$ Bernardo ha leído el Ascl en la biblioteca de la Escuela de Chartres, $2^{\circ}$ la presencia y equivalencia en ambos de Imarmene (Cosm II,ii,8, Asc 19), $3^{\circ}$ cita textual en relación con el gobernador de los cielos Pantomorphos(Cosm $11, i i, 11$, Asc 19), $4^{\circ}$ registro de los ojarses (=oy[si]arses) paralelos a los ousiárchai o arcontes herméticos de los diversos sectores del cosmos (Cosm II,ii,11; v,4ss., Asc 19 y ver NHC VI, 63,15-20), $5^{\circ}$ el hombre en ambos escritos es celeste y terreno y por poseer ambas cualidades puede cuidar a la tierra, siendo su tarea pontifical (Cosm II,x y Asc 6-7-8 y 27). La reciente traducción de M. Lemoine ha enriquecido los paralelos con el Asc y al pasar ha advertido la relación entre Nous en II,ii, 8 y Asc 41 (o.c. en n. 75 , 59, n. 1).

78 Cf. Mahé, J.-P., Hermès en Haute-Égypte I, Québec, Les Presses de l'Université Laval, 1978, 164-165, con los textos trilingües.

79 Cf. Ascl 21: «Utriusque sexus ergo deum dicis, oh Trismegistus?- Non deum solum, Asclepi, sed omnis animalia et inanimalia, inposibile est enim aliquid eorum quae sunt, infecundum esse», que depende del principio de origen y continuidad: «Non enim hoc dixi, omnia unum esse et unum onnia, utpote quae in creatore fuerint omnia, antequam creasset omnia?... at vero quicquid de alto descendit generans est; quod sursum versus emanat, nutriens» (2, ver asimismo 9). Lactancio no era tan audaz, ver fr. 13.

80 El tema neoplatónico de la alteridad (heterótes) como Penía en Ascl 14, 15 y 17:»Hyle autem vel mundi natura et spiritus quanvis nata non videantur a principio» (en esto difiere Bernardo) «tamen in se nascendi procreandique vim. possident atque naturan fecunditatis etenim initim in qualitate naturae est...utpote qui is onnibus ad concipiendum fecundissimus simus praestet... Hyle autem vel mundum omnium est receptaculum omniumque agitatio atque frequentatio». 
$4^{\circ}$ La necesidad o insatisfecha inquietud propia de la materia por ser formada, pero bellamente, o sea, ajustándose cuanto más le sea posible a la forma, generando vástagos o imágenes bellas, una necesidad que llega a ser clamor de Naturaleza al dirigirse al semillero de vida, luz y belleza, a Nous, ${ }^{81}$

Pero en este caso el concepto que se maneja de la belleza y su producción es doble y abarca tanto la concepción platónico pitagorizante del ente bello como imagen cósmica de acuerdo con las proporciones aritmética, geométrica y armónica que enlazan dimensiones, figuras e intervalos de un viviente en el tiempo y el espacio, ${ }^{82}$ como otra perspectiva, la de la imagen como estatua que adquiere vida por semejanza divina, una creencia propia de la teúrgia y el hermetismo del Asclepio y que permite la producción y transformación del mundo, en cada uno de sus planos, partes y rincones como un «icono del cielo» (imago caeli). ${ }^{83}$

En este aspecto Bernardo es profundamente original y vence a favor de la causa cristiana ortodoxa lo que puede realmente llamarse la batalla por la estética, una concepción ajena tanto a la filosofía del arte griego como al trascendentalismo gnóstico y al encratismo monástico.

Las Enéadas de Plotino son ejemplares para el primer cáso. En ellas se enšeña una sublime filosofía de la belleza y hasta el punto de que los peldaños que manifiestan su resplandor en los seres hacen ascender al contemplador ontológica y autorrealizativamente, hasta identificarse en el Uno/Bien, una vez superada la sobria embriaguez de la luz inteligible. ${ }^{84}$ Pero cuando se trata de la obra de arte, por más que el artista se eleve rápido con su contemplación para captar los principios conformadores de la naturaleza y éste sea para él el secreto de la imitación ${ }_{1}^{85}$ pudiendo corregir fallas de contemplación y completar al mismo cosmos, sus obras comparadas con las del demiurgo no son más que «juguetes de niños» (paignia). Pero lo mismo sucede con las almas humanas, son capaces del contacto súbito con el Bien cuando por la virtud han «plasmado la propia estatua», pero siempre condenadas al descenso en la rueda del universo sin comienzo ni fin. ${ }^{86} \mathrm{Es}$ que la belleza verdadera se identifica con el brillo de lo que realmente es.

Calcidio cuyo Comentario incluye casi toda la filosofía del platonismo, interesa en la síntesis final en la que silva como sustrato universal, es posibilidad de recibirlo todo quedando siempre materia. La síntesis se apoya en la exposición previa (c. Jensen, P.J.Waszink, J.H., Timaeus a Calcidio iransiatus commentarioque instructus, London-Leiden, Brill, [Plato Latinus IV] 1962, 351-354 (pgs. 341-346) y 268 (273,15-19); 273 (277,16-278,2); 278 (291,16-292,3); 308-310 (309-310); 316-318 (312-314) y 334 (327-328) y van Winden, J.C.M., Calcidius on matter his doctrine and sources, Leiden, Brill, $1965,232-242$, y $32-33,88-89,143-152,160-163$ y 198-200). Los antecedentes, García Bazán. F., Neoplatonismo y Vedânta. La doctrina de la materia en Plotino y Shankara, Buenos Aires, Depalma, 1982, 1-128.

81 Cf. Ascl: «Sicuti enim in natura materiae qualitas fecunda est, sic et malignitatis eadem est aeque fecunda», por lo tanto: «siquidem, cum dei opera sit mundus, eius pulchritudinem qui diligentia servat atque auget, operant suam cum dei voluntate coniungit, cum specient, quan illa divina intentione formavit, adminiculo sui corporis diumo epere curaque conponif $»$ (15 y 11, resp.), cuando el fin se malogra llega la denuncia apocalíptica: eNam et tenebrae praeponentur lumini et mors vita utilior iudicabitur; nemo suspiciet caelums (25 y 26).

82 Cf. Cosmografia I,ii,7. Es el ideal del demiurgo del Timeo, explicado por Jámblico, De conm. math. scienita 31 in fine; 57,$16 ;$ Int. Arith. Nich. 79 y que Calcidio, Macrobio y Boecio recogen.

83 Cf. Ascl 23 y 24 y recuérdese el impacto sobre Agustín, n. 35.

84 Cf. En VI,7 (38), 35-36.

85 Cf. En V,8 (31), 1 nuestro comentario en Plotino y la gnosis, Bs.As., FECIC, 1981, 81-84.

86 cf. En IV,8 (6), I y García Bazán, F., Aspectos inusuales de lo sagrado, cap. III: «La mística y el lenguaje de la místicas. 
Cuando se lee la Cosmografía de Bernardo Silvestre y se percibe su esfuerzo por liberar a lo femenino y a la materia de su condición de sempiterna menesterosa, no se puede dejar de recordar como antítesis, aquel escrito también enigmático que Hipólito de Roma consiguió no sabemos cómo y estampó en su Elenchos, el Libro de Baruc del gnóstico Justino. También en él Edén, el principio femenino, ha creado con el Padre Elohim el mundo, pero éste la ha abandonado una vez que ha visto al Padre Bueno y él lo ha sentado a su derecha. Los males del mundo provienen del abandono por el consorte de la esposa, criatura que es doble, mezcla de doncella y de serpiente. Todo el esfuerzo de los gnósticos ha consistido en la liberación de 10 pneumático, encerrado en un cosmos viviente, originado en el error de Sabiduría y que el deseo preocreador conserva. El ideal de la belleza en este caso es irreductiblemente espiritual y la actitud antinaturalista y anticósmica es el camino que hay que recorrer para gozar perennemente de ella. ${ }^{87}$

Para Bernardo, sin embargo, la belleza sin soporte corporal carece de sentido, y el soporte sin suficiente animación no es bello. Su insistencia sobre lo femenino que aspira a formarse y a generar un hijo, como la identidad propia de la matriz ${ }^{88}$ se supera con la idea de que la necesaria combinación de la materia y la forma para que sea bella o un mundo con omato, debe ser una mostración estable de la incorporación de la estructura formal en el soporte dispuesto que la reclama. De este modo la transformación de la materia que todo lo anhela ilimitadamente y la fusión de ambos que logra permanencia, es el eje principal y salvífico.

La antigua preocupación filosófica cristiana sobre el modo posible de la Encarnación del Verbo, basada en las reflexiones sobre la unión del alma y el cuerpo, estriba en la misma intuición. Los ecos trasmitidos por los neoplatónicos alejandrinos de los análisis de Juan Filopono entre las posibles combinaciones íntimas, por yuxtaposición (parathésis), mezcla (míxis) y fusión (krâsis), que tanta utilidad prestaron a la cristología del Concilio de Calcedonia y que adoctrinaran incluso a los filósofos árabes, ${ }^{89}$ son retomados ahora en el ámbito de la cosmología, la antropología y la estética. Pero en esta epopeya sotérica la gran protagonista para Bernardo es la dimensión femenina y con ello la exaltación de lo sensible. La capacidad de lo femenino que aspira a la forma, receptora universal e inseparable de su contraparte informadora, puesto que la vida practicable confirma que no hay fuga, soledad ni aislamiento del mundo que aporte felicidad, sino el encuentro amoroso, la pareja de opuestos abrazada y su brillante combinación armónica. Bernardo es Silvestre, porque es el gran defensor de la imprescindible contracara femenina necesaria para que haya un mundo completo y bello. Un mundo que redime a la materia, vivo, poliforme, policromo y variado, pero estable, por la presencia de la sustancia y las proporciones matemáticas que lo invaden y enlazan. En última instancia colaborando en la obra redentora del Dios hecho hombre, Bernardo es el posibilitador de una filosofía cristiana del arte, representada paradigmáticamente por la aventura del

87 Texto en García Bazán, F., Grosis. La esencia del dualismo gnóstico, S. Antonio de Padua (Bs.As,), Castañeda, 19782, 291-297.

88 Cf. Timeo $91 \mathrm{C}$ y ver García Bazán, F, «Los gnósticos y el lenguaje de la sexualidad», en EPIMELELA, IV/8 (1995), 183-199.

89 Cf. MacCoull, «A New Look at the Career of John Philoponos», en Journal of Early Christian Studies 3n (1995), 47-60. 
universo y el hombre como imágenes vivientes, y el restaurador intelectual y liberador de Silva, sin cuya presencia lujuriante en el mundo y el cumplimiento de sus impulsos más profundos por medio de Naturaleza, no habría designio providencial, ni creación ni ente ni belleza, es decir, sólo habría Nada, pero sin amor, un Dios abstracto. ${ }^{90}$

Francisco García Bazán

San Lorenzo 2393

1640 Martínez (Buenos Aires)

R. Argentina- Telefax- 54-11-4798-2311

90 La influencia de la Cosmografia llega a Juan de Meung, Bocaccio y Dante Alighieri. Las líneas de Eco, U., La estética medieval, Barcelona, Lumen, 1998, Cap. IV, deben leerse como «compendio», para evitar las arbitrariedades. 